\title{
ENGELMANN'S DISEASE
}

\author{
Report of a Case with a Review of the Literature
}

\author{
Evan A. Lennon, ${ }^{*}$ Brisbane, Australia \\ MANNiE M. Schechter and Richard W. Hornabrook, \\ New York, United States of America \\ From the National Hospital for Nervous Diseases, Queen Square, London, England
}

Engelmann in 1929 reported a " new" disease, which he called osteopathia hyperostotica sclerotisans multiplex infantilis, and which he believed to be connected with a disturbance of the haemopoietic system. A boy, eight years of age, had complained of pains in the legs for four years. He had a short neck and trunk, long limbs, weak musculature, lumbar lordosis, flat feet and a waddling gait. There was palpable swelling of the long bones of the upper limbs. The spleen was enlarged and the testicles were small. Examination of the blood showed lymphocytosis, slight monocytosis and eosinophilia. Radiographs showed symmetrical elongation and slight curving of the long bones with thickening and sclerosis of the diaphyses. The epiphyses and joints were normal. There was sclerosis of the frontal bone and skull base.

Sear (1948) described a similar case of bone disease, and drew attention to Engelmann's paper. He gave the condition the eponymous title of Engelmann's disease.

Before Engelmann's description Cockayne (1920), at a meeting of the Royal Society of Medicine, had presented a case for diagnosis, which Fairbank (1951) subsequently recognised as probably belonging to this syndrome. Despite a thorough search through the National Registry in London, no record of this patient could be found. If still alive the patient would be forty-eight years old.

Camurati (1922) reported " a rare case of hereditary symmetrical osteitis of the lower limbs" in a boy aged seven. The clinical features and radiographic appearances resembled those of Engelmann's patient. The fifty-five-year-old father of this boy also had a history of leg pains in youth, and radiographs showed an increase in density and thickening of the shafts of the bones in both lower limbs. Seven other members of the father's family in four generations had a similar history, but were not investigated.

A number of similar patients have been reported; so the natural history of the disorder is now identifiable. Excluding the patient we are reporting, fifty-one others have been traced.

Other authors followed Camurati in drawing attention to the familial nature of this disorder. Lauterburg (1931) described "generalised familial sclerosis" in a boy aged sixteen years and in his father aged forty-two. Cocchi (1951) identified these two patients as belonging to Engelmann's syndrome and he pointed out that they had been under observation for twenty years. Ortolani and Castagnari (1953) described the condition in two siblings. Ribbing (1949) reported a family of six siblings, four of whom in the third decade showed increased density and widening of the diaphyses of the femora and tibiae; he said that Feddema found five siblings affected in the fifth and sixth decades of life. Paul (1953) described a man of twenty with this condition. His brother aged thirty-five and infant son had the same abnormalities. Jammes, Seruz, Prouxet and Duclos (1953) reported a case in a man aged twenty-two years. A brother and a sister were also affected. Buchem, Hadders and Ubbens (1955) also described a familial case. Roth (1957) reported an eighteen-year-old youth whose father and fourteen-year-old brother were similarly affected.

Sporadic cases without family history have also been reported by Fritsch (1933), Riley and Shwachman (1943), Neuhauser, Shwachman, Wittenborg and Cohen (1948), Wiedemann

\footnotetext{
* Holder of Thomas Baker Memorial Fellowship.
} 
(1948), Michaelis (1949), Casuccio (1949), Bingold (1950), Stronge and McDowell (1950), Gvozdanović (1950), Fairbank (1951), Le Bien and Heilman (1951), Gulledge and White (1951), Gillespie and Mussey (1951), Lavine and Koven (1952), Anderson (1953), Jammes et al. (1953), Perassi (1954), Weingraber (1954), and Singleton, Thomas, Worthington and Hild (1956).

Griffiths (1956) described a single patient and reviewed twenty-two previously reported cases. He also drew attention to the radiographs of a patient with this disorder published by Geschickter and Copeland (1949) which is referred to in the text as of an unclassified juvenile bone dystrophy. Most of these were diagnosed in childhood, although sometimes symptoms first appeared in adults. Thus Michaelis (1949) reported the disease in a woman twenty-nine years old, and Stronge and McDowell's (1950) patient did not develop symptoms until he was twenty-eight years old.

Griffiths (1956), Anderson (1953), Jammes et al. (1953) and Perassi (1954) all reported the condition in adults, and Buchem et al. (1955) in two siblings, both of whom developed symptoms in middle life.

The range of bones involved has gradually been extended, and the evolution of the disease has become clearer. Fritsch (1933) reported a woman, thirty years old, whom he had had under observation for ten years. When first examined in 1923 she gave a history of having been frail as a child, and of having pain in the right leg for six years. There was a soft, tender swelling over the right tibia, and the radiographs showed a cortical thickening with diminution in the marrow space in the diaphysis. Later her left leg and arms became painful, with progressive changes showing in the radiographs; by 1932 the femora, tibiae, humeri and the anterior and middle cranial fossae were also involved.

Ribbing's (1949) family of six siblings developed increased density and widening of the diaphyses of the femora and tibiae. Three of these patients had leg pains, but another had no symptoms. Ribbing pointed out that the disease was progressive, but appeared to be self-limiting.

Gvozdanović (1950) described a three-month-old girl, who died of anaemia, and in whom radiological changes were very extensive, and even involved the ribs, the clavicles and the vertebrae.

Le Bien and Heilman (1951) had one patient with radiological changes in the metatarsals. Anderson (1953) is the only author who has seen changes extending into the head of the femur. Paul (1953) described a man who was first seen in 1941, at the age of twenty, complaining of swelling over the right tibia, which showed a fusiform swelling in the radiograph. In 1948 the patient complained of swelling in the left leg, and it was found that both the tibiae, the femora, and the right radius had the radiological appearances of Engelmann's disease. His family were then investigated, and his brother, aged thirty-five, whose only complaint was of episodes of double vision, was found to have typical radiological changes in both tibiae, the left femur and the left ulna. He also had a left-sided otosclerosis. Jammes et al. (1953) reported a man aged twenty-two, who had the history, physical signs and radiological changes of Engelmann's disease. This man had asymmetry in the length of the limbs, with the right arm longer than the left, and the left leg longer than the right. Jackson, Hanelin and Albright (1954) reviewed two patients previously described by Neuhauser et al. (1948) in the light of further observations. They drew attention to the fact that sometimes two separate diaphysial foci of bone expansion were seen in the femora with the intervening shaft less intensely involved or almost spared. Caffey (1956) saw that an area of bone in the region of the nutrient foramen was spared. Weingraber (1954) found that the newly formed periosteal bone in the long bones of a boy of four showed an " onion peel " structure which quickly became consolidated with the shaft, which increased three millimetres in thickness in two months.

Riley and Shwachman (1943) published two cases of " unusual osseous disease with neurological changes" in a boy and girl both aged five. The neurological features were hyperactive deep tendon reflexes and an inconstant ankle clonus. Other neurological findings, 


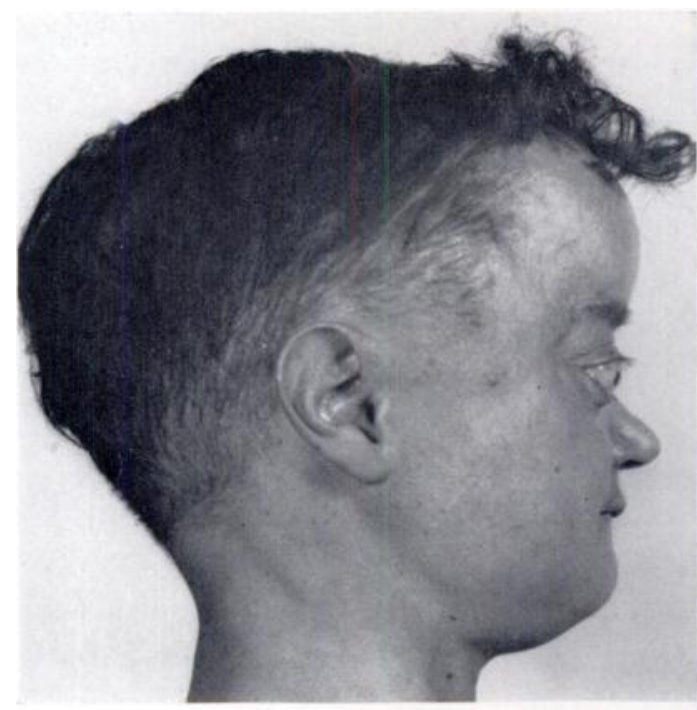

FIG. 1

FIGs. 1 AND 2

Figure 1-The clinical appearance, showing the enlarged head, prominent forehead, and small juvenile face with proptosis.

Figure 2 -The limbs are unequally long and thick, with small hands and flat feet. There is lumbar lordosis and disproportion between the size of the limbs and the trunk.

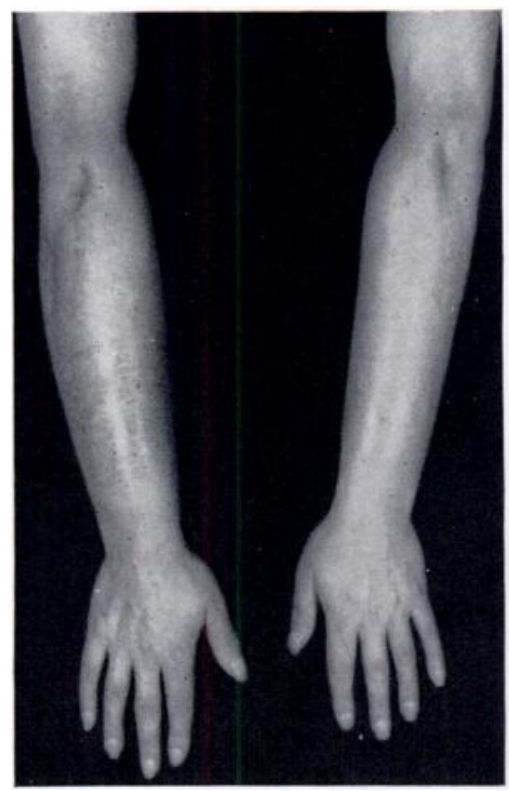

Fig. 3
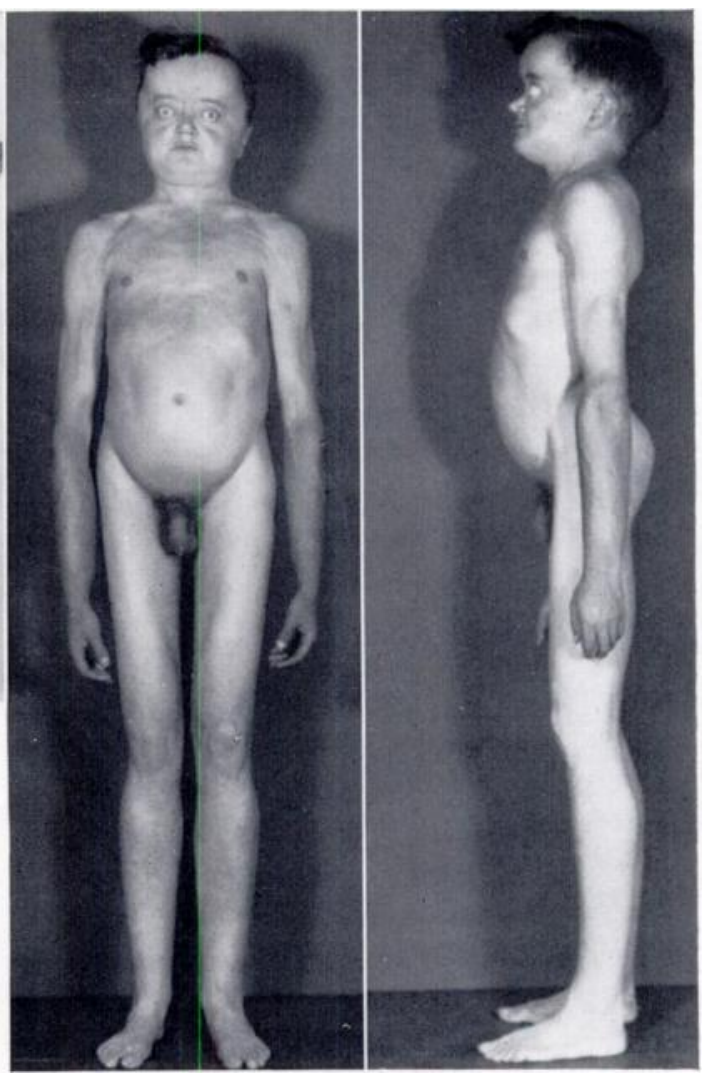

FIG. 2

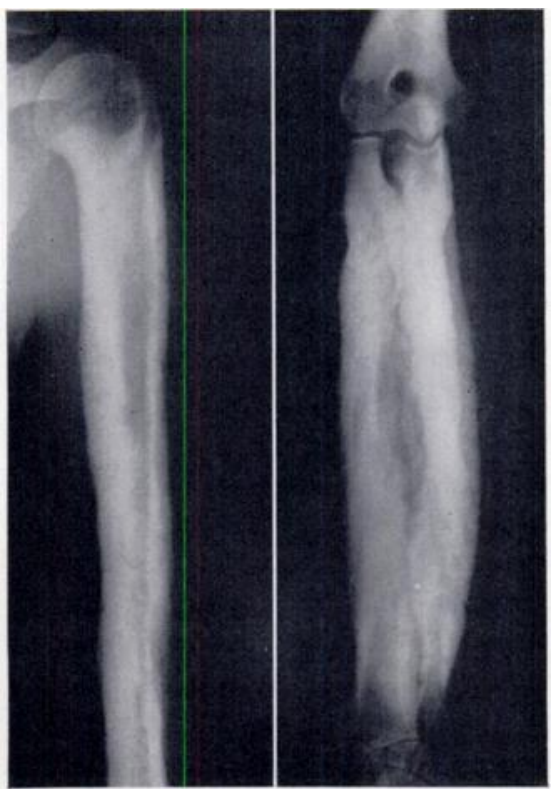

Fig. 4

Figure 3-The increased width of the limbs is because of thickening of the bones, despite muscle wasting. The skin is rough, thick and dry. Figures 4 and 5-The shafts of the left humerus and right radius and ulna showing the absence of the normal trabecular pattern and an increase in density and width. The changes are most marked in the centre of the diaphysis but they reach almost to the epiphyses. The surface of the shaft is uneven. Note the proliferation of the cortex at the expense of the medulla. 
of diplopia and otosclerosis, were reported by Paul (1953). The description of a waddling gait is common. Buchem et al. (1955) reported a man of forty-eight, who gave an eleven-year history of an enlarging head, failing vision, increasing deafness, occasional vertigo, stabbing headaches and muscle weakness. He was well built, with a high forehead, a prominent chin, slight enophthalmos, bilateral optic atrophy, poor thoracic movement and a dry flaky skin. Le Bien and Heilman (1951) found that the skin over the extremities felt hard and woody, as in scleroderma, and the man described by Buchem et al. (1955) had a hard, dry flaky skin. Some suggestion of endocrine insufficiency has been made. Thus Jammes et al. (1953) reported a slight decrease of 17-ketosteroid excretion in their patient. The woman reported by Buchem et al. (1955) had scanty axillary and pubic hair. Later she died of broncho-pneumonia but, apart from multiple subperiosteal excrescences on the bones and the widening of the cortices and diaphyses, there were no significant abnormalities.

\section{CASE REPORT}

A thirty-four-year-old man was admitted to the National Hospital for Nervous Diseases, under the care of Dr S. P. Meadows, complaining of headaches for five years and deafness for three months. An older brother of the patient had been treated for epilepsy and mental deterioration in the same hospital when an infant, and bossing of the frontal bones was remarked upon at the time. This brother died at home, aged twenty-one years, in status epilepticus, and necropsy was not performed. There were no other siblings and the parents and their relatives had had no nervous, mental or skeletal disease.

The patient was believed to have developed normally until the age of eighteen months, but when he started to walk his gait was abnormal, being shuffling and awkward. At ten years of age enlargement of the head was obvious and his limbs were of a "peculiar" shape. He was considered too delicate to go to school and consequently was largely self-educated. All his life he had been liable to attacks of epistaxis.

For five years before his admission he had been troubled by episodes of vertigo culminating on several occasions in brief disturbances of consciousness; over the same period occipital headaches, gradually increasing in frequency, made their appearance. Eventually an almost continuous generalised throbbing headache forced him to seek medical advice.

He had a massive enlargement of the head, the greatest circumference being twenty-seven and a half inches. The forehead was high and prominent. The small face was juvenile in appearance with a marked proptosis. The long, thick limbs were in striking contrast to the small hands and feet. The right arm was longer than the left. The arms had a peculiar cylindrical appearance due to the lack of musculature combined with an increase in width of the bones (Figs. 1 to 3 ).

There was thoracic kyphosis, marked lumbar lordosis and valgoid flat foot. The arm span was seventy-two and a half inches and the height seventy inches. The circumference of both the upper arm and forearm was nine and a half inches. The skin was thick, rough and dry. There was no beard or axillary hair and very little pubic hair. He was intelligent but the voice was quiet and juvenile. The external genitalia were infantile. The gait was stiff and shuffling, suggesting a toy soldier, and he was unable to pronate and supinate the forearms. All the deep reflexes were brisk and there was generalised muscular weakness. There was no disorder of sensation; the plantar responses were flexor. The blood pressure was 180/100 millimetres of mercury and remained consistently elevated. He had severe dental caries (Fig. 13).

Neuro-otological findings (Dr C. S. Hallpike)-There was a suggestion of eighth nerve involvement by bony changes; there was bilateral deafness, that of the left ear being perceptive and of the right conductive. There was spontaneous vestibular nystagmus to the left and the left caloric responses were abolished and the right reduced.

Ophthalmological findings (Mr Keith Lyle)-There was optic atrophy on the right. The left disc was pale but probably normal.

VOL. 43 B, NO. 2, MAY 1961 


\section{CLINICAL INVESTIGATIONS}

The examination of the blood gave the following results: Red blood count $-5,200,000$ per cubic millimetre. Haemoglobin-16 grammes per cubic millimetre. Colour index-1. Packed cell volume-50 per cent. Mean corpuscular volume-9 to 6.1 cubic microns. White blood count $-7,000$ per cubic millimetre. Differential white cell count-normal. Erythrocyte sedimentation rate-26 millimetres in one hour. Wassermann reaction-negative. Serum protein 6.4 grammes per 100 millilitres with a relative increase in the alpha globulin fraction. Serum calcium 10.4 milligrams per 100 millilitres. Serum phosphorus 4.3 milligrams per 100 millilitres. Serum alkaline phosphatase 23 King-Armstrong units. Serum cholesterol 210 milligrams per 100 millilitres.

The cerebrospinal fluid was normal, including the Wassermann reaction. The liver function and iodine uptake tests were also normal and the patient was able to excrete a water load within four hours with a normal rate of dilution. The electro-encephalograph showed a slight increase in fast activity.

\section{RADIOLOGICAL FINDINGS}

Long bones-There was an absence of the normal trabecular pattern with an increase in density and width of the shaft, most marked in the central part of the diaphysis but extending almost to the epiphysis. The outer margin of the shaft was uneven. The medulla was almost completely replaced by cortical expansion. These appearances were seen in all the long bones (Figs. 4 to 8).

Hands and feet-There was an increase in density of the shafts of the metacarpals and metatarsals with little widening. Similar but less marked changes were present in the phalanges (Figs. 9 and 10).

Pelvis-Dense areas were present in the ilium and ischiopubic rami on both sides, particularly the right (Fig. 11).

Skull-The base and all the calvarial bones were grossly thickened and dense except in the region of suture lines. The mandible was also affected but the facial bones were normal (Fig. 12).

Vertebrae-The cervical and upper thoracic vertebral bodies were flat but no more dense than normal (Fig. 13).

Ribs-There was a slightly increased density (Fig. 14).

Clavicles-These were dense and thick.

Scapulae-There were some dense areas in the bodies.

Air encephalograph-The ventricular system was normal in size, shape and position.

\section{DISCUSSION}

It is rare to find any two patients with a syndrome who are exactly alike, and the variation may be such that one may appear to have some manifestations of a second syndrome. After reviewing the literature on Engelmann's disease, we found it difficult to draw a clear-cut distinction between typical and borderline cases, particularly without personal knowledge of the patients concerned. Thus Paul (1953) compared his patients with those of Fritsch (1933), Ribbing (1949) and Feddema (Ribbing 1949) and observed that they showed features different from those of Engelmann's disease, because the latter had more widespread and symmetrical lesions, which had appeared at an earlier age and which were associated with disturbances of gait and posture. Later, however, Paul revised his opinion when he described the infant son of his first patient, who had all the typical features of Engelmann's disease.

Buchem et al. (1955) considered that their patients resembled those with Engelmann's disease, but did not feel that they should be classified as such. These patients, however, so closely resemble the patient described here that it seems certain that they should be included in 


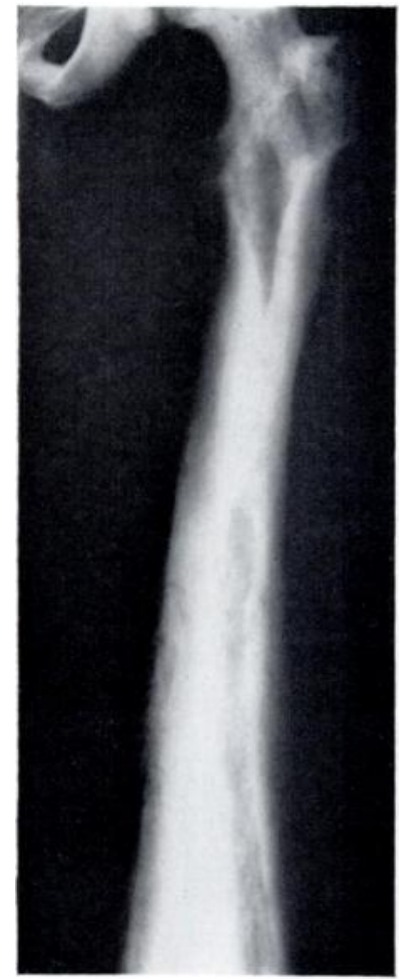

FIG. 6

FIGS. 6 To 8

Figure 6-The left femur shows the same changes as those in the other long bones.

Figure 7-The lower ends of right and left femora and upper ends of both tibiae and fibulae show that the bone changes extend almost to the epiphyses. Figure 8-The right and left tibiae and fibulae show the same changes as the other long bones.

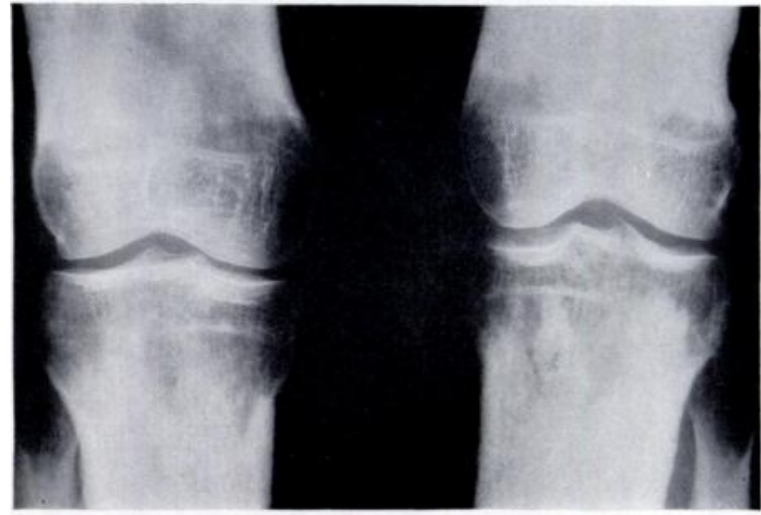

FIG. 7

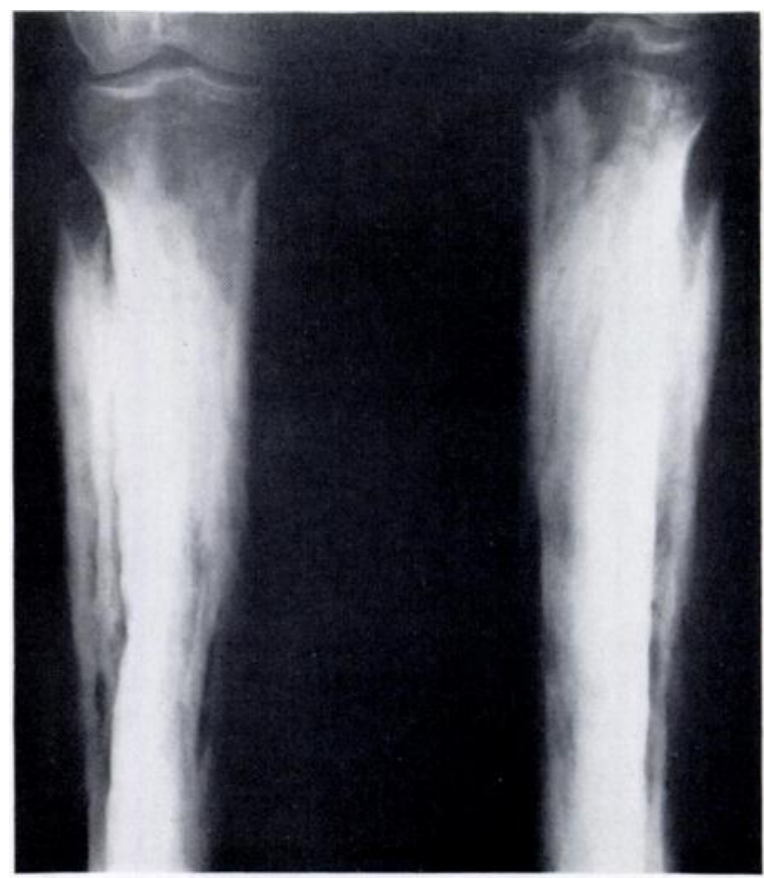

FIG. 8

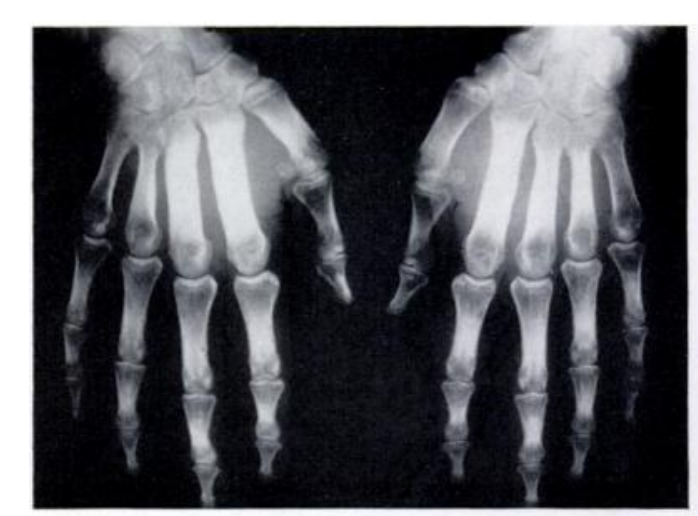

FIG. 9

The radiographs of the hands (Fig. 9) and feet (Fig. 10) reveal an increase in the density of the mid-shafts of the metacarpals, metatarsals and phalanges, particularly in the second, third and fourth rays. 
this syndrome. A condition which the authors consider to be different from Engelmann's disease is leontiasis ossea with generalised bone changes as reported by Garland (1946) and Pygott and Scott (1954). We could find no patient with generalised bone sclerosis among the patients with leontiasis ossea described by Knaggs (1926).

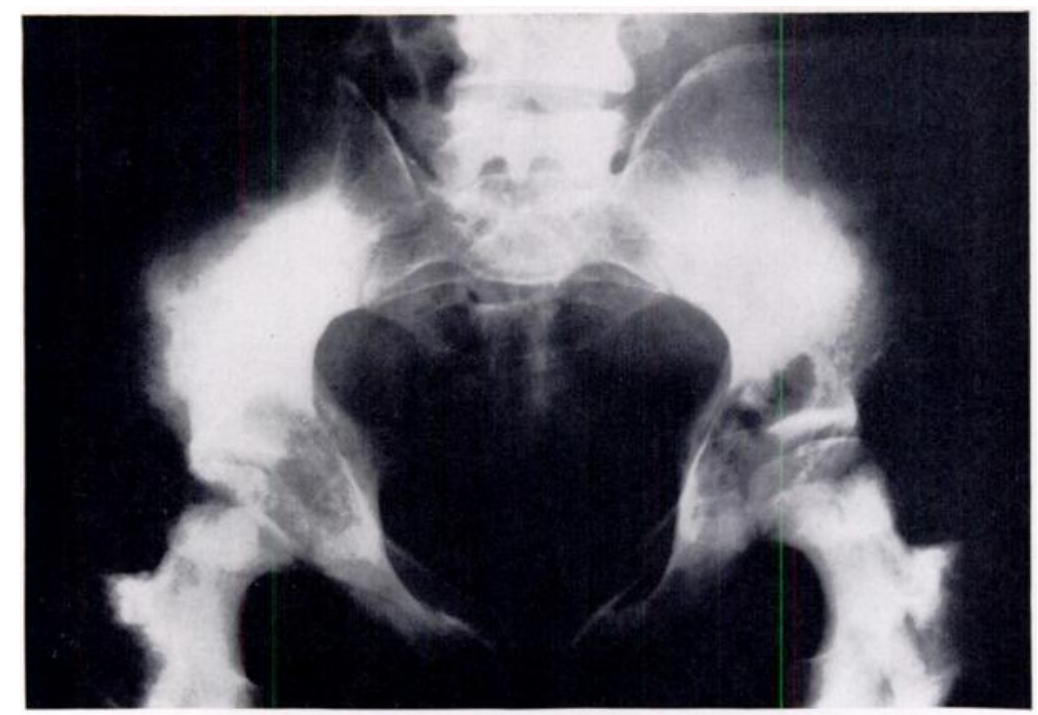

Fig. 11

The radiograph of the pelvis shows dense areas in the ilium and ischiopubic rami on both sides but more on the right. The femoral heads are flattened and there is a valgus deformity of both femoral necks.

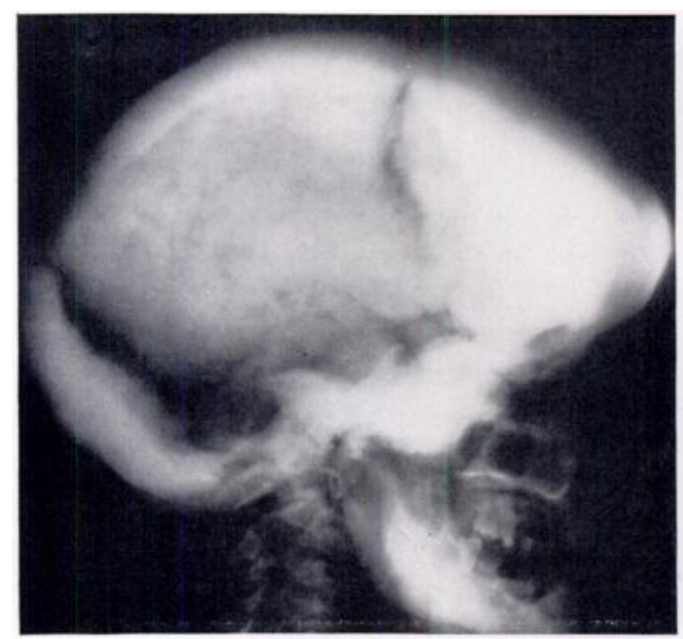

FIG. 12

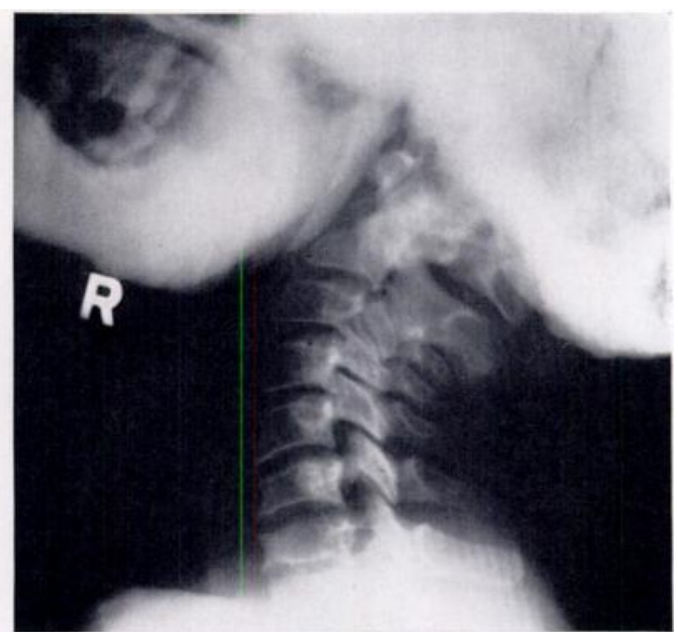

Fig. 13

Figure 12-A radiograph of the skull shows that the base and all the calvarial bones are thickened with sparing of bone adjacent to the sutures. There is enormous thickening of the frontal bone and the mandible is also affected. Figure 13-Radiograph of cervical vertebrae. Note the flattening of the bodies of the vertebrae, without increase in density. Note the dense mandible and marked dental caries.

The condition known as generalised hyperostosis with pachydermia or pachydermoperiostitis (idiopathic osteoarthropathy) resembles hypertrophic osteoarthropathy. It begins at puberty with intermittent swelling of the hands and feet, increased width and length of the limbs, and is sometimes associated with pachydermia of the forehead and scalp. Radiologically 


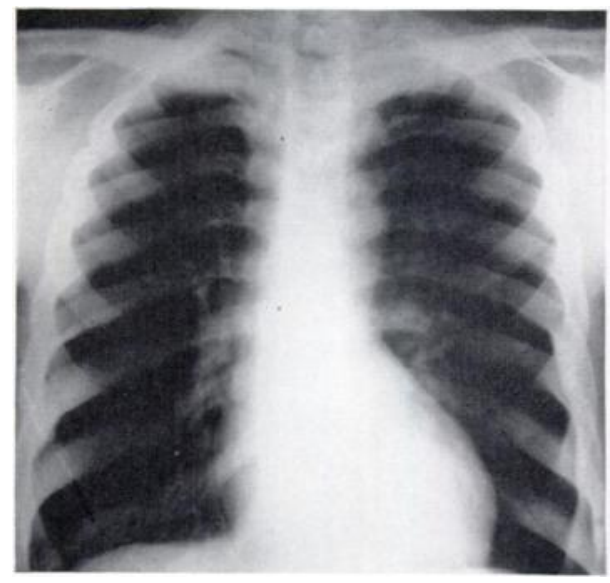

FIG. 14

Radiograph of chest showing slight increase in density and thickening of the ribs. The clavicles are affected and there are some dense areas present in the bodies of the scapulae.

the appearance of the bones resembles that of the most severe forms of Engelmann's disease except that there is a heavy, widely spaced trabecular pattern, rather different from the amorphous appearance in Engelmann's disease.

This discussion embraces fifty-two patients whom the authors consider to have had Engelmann's disease, including our own patient. The patients of Cockayne (1920), Ribbing (1949), Fritsch (1933), Feddema (Ribbing 1949), Lauterburg (1931), Buchem et al. (1955) and Farreras Valenti, Vilaseca and de Caralt (1954) have been included, but not those with leontiasis ossea with generalised bone changes or those with hyperostosis generalisata with pachydermia, although these conditions do possibly bear some relation to Engelmann's disease. Griffiths (1956) and other authors were of the opinion that Ribbing's report of his own and Feddema's patients had another disease, but when they are compared with those of Paul (1953) there seems to be little difference. Age-The age was not stated in two patients. Of the remaining fifty the age at which symptoms started is shown in Table I. The youngest patient was three months old, and the oldest fifty-six years.

TABLE I

Age at which the Symptoms of Engelmann`s Disease Started

\begin{tabular}{|l} 
Age in years . \\
Number of patients
\end{tabular}$\frac{0-10}{19} \frac{11-20}{8} \frac{21-30}{11} \frac{31-40}{3} \frac{41-50}{4} \frac{51-60}{5}$

Sex-There were thirty-one men and twenty-one women.

Race-Reports come from many parts of Europe, the United States of America, Canada and Australia. Wiedemann's (1948) patient was said to be of mixed German, Spanish and Negro descent, and there have been patients from an Iraqui family (Roth 1957) and a Filipino (Gulledge and White 1951). Lavine and Koven's (1952) patient was a Jew.

Heredity - It is likely that a genetic trait exists, for there are nine examples of familial incidence: father and son (Camurati 1922), four siblings (Ribbing 1949), five siblings (Feddema, cited by Ribbing), father and son (Lauterburg 1931), two siblings and a son (Paul 1953), two siblings (Ortolani and Castagnari 1953) and a father and two sons (Roth 1957).

Symptoms and signs-Pains in the limbs were present in twenty-three patients; described as aching or stabbing in nature and usually intermittent, the pain was worse after exercise and sometimes worse at night. A common site for the pain was one or both legs below the knee.

Being easily tired, delay in starting to walk, and being unable to run about are probably related to muscular weakness, which may be also responsible for the abnormal gait (twenty-five patients), lumbar lordosis (ten patients), flat feet (ten patients) and valgus deformity of the ankles (four patients). Thin legs or poor musculature were found in twenty-two patients, and an interesting observation was that in twelve patients the limbs seemed disproportionately long in comparison with the trunk and in two patients the bones were of unequal length. Failure to thrive, retarded growth or general underdevelopment was seen in thirteen patients. Signs of delayed puberty, hypogonadism, diminution of secondary sex characteristics, absence of pubic, axillary or facial hair were found in eleven patients. 
A dry hard skin has been mentioned in five patients and absence of the subcutaneous fat layer in three.

Gross dental caries was a common finding. Four patients had a history of delayed dentition and in three the teeth were said to be widely spaced.

The presence of proptosis in six patients can be explained by diminution in the size of the orbital cavity from expansion of the surrounding bone; a decrease in the size of the cranial cavity and in the exit foramina of the eighth nerve probably accounted for the headache and deafness in four patients. Tendon reflexes in the affected limbs have usually been hyperactive but in four patients were hypoactive. Engelmann's own patient and four others were mentally dull.

Four patients had enlarged spleens and seven were anaemic.

An arbitrary division of patients into three groups can be made according to the severity of the disease.

Severe type-These usually have the typical posture and gait and a history from infancy of leg pains and difficulty in walking with or without muscle weakness. Most are diagnosed before puberty, but Stronge and McDowell's (1950) patient was twenty-eight, Michaelis's (1949) was twenty-four, and our patient was thirty-four.

Moderate type-These patients have either a history of past symptoms-such as the father described by Camurati (1922) - or a history of recent onset. Some have the typical posture and gait, but others are of normal physique. The bone changes are usually confined to a short length of the diaphysis in a few bones only, but they may be more extensive and out of proportion to the moderate severity of the clinical findings.

Mild type-These patients are asymptomatic and have been diagnosed radiologically on investigation of the families of patients belonging to the severe or moderate group. Examples are found in the reports of Ribbing (1949) and Paul (1953).

A family that has two or more of its members belonging to different groups suggests that these patients are suffering from different degrees or stages of the same condition.

Radiological changes-At any particular age the radiological changes vary with the severity of the clinical picture and are more marked in patients with a long history and in those with muscular weakness.

Usually the radiological progress is slow, but in Weingraber's (1954) case it was rapid. The changes start at any age and may become stationary. Bone has been seen to re-form in six weeks after biopsy (Singleton et al. 1956).

At first there is an increased density and widening of the cortex of the tibial or the femoral diaphysis on one or both sides, with a slight fusiform enlargement, but a smooth surface. These changes may start anywhere in the diaphysis but usually in the middle third.

Gradually the affected area involves the shaft towards the metaphyses and other bones may become affected. Later there is considerable encroachment on the medullary cavity, the width of the shaft increases, and the surface of the bone becomes irregular.

Finally the medullary cavity becomes almost obliterated and the whole bone, with the exception of the epiphyses, has a dense, amorphous appearance, less severe near the medullary cavity and epiphysis. The surface of the bone is now very irregular, but, because of increase in width of the whole shaft, the diameter of the bone is almost uniform throughout its length.

\section{THE AFFECTED BONES}

In the long bones the changes are usually bilateral and symmetrical. Two of Feddema's patients (Ribbing 1949) and one of Ribbing's (1949) had isolated bones affected as did Fritsch's (1933) patient when first seen. Unilateral involvement of one bone with bilateral affection of other bones has also occurred (Figs. 15 and 16).

Involvement of the tibia was most common, being present in forty-seven patients. The femur, fibula, humerus, radius and ulna followed in that order of frequency.

VOL. 43 B, NO. 2, MAY 1961 
The base of the skull was affected in twenty-seven patients, usually in the anterior and middle fossae. In the vault the frontal bone was most frequently involved, usually with the density extending upwards from the orbital plates. No calvarial bone is exempt, and the facial bones have been affected in four patients. Narrowing of the exit foramina of the cranial nerves caused neurological changes in four patients.

When the pelvis is involved it is usually in the ilium near the acetabulum and close to the sacro-iliac joints.

Increase in density of the vertebrae has been mentioned in five patients; in four of these it was only the cervical vertebrae, and in two only the atlas, or the atlas and axis, that were affected, but all the vertebrae were affected in the patient reported by Gvozdanovic (1950).

Roth (1957) remarked on the flattened vertebral bodies in his first patient. In our patient lateral radiographs of the spine show that the antero-posterior dimension of the vertebral

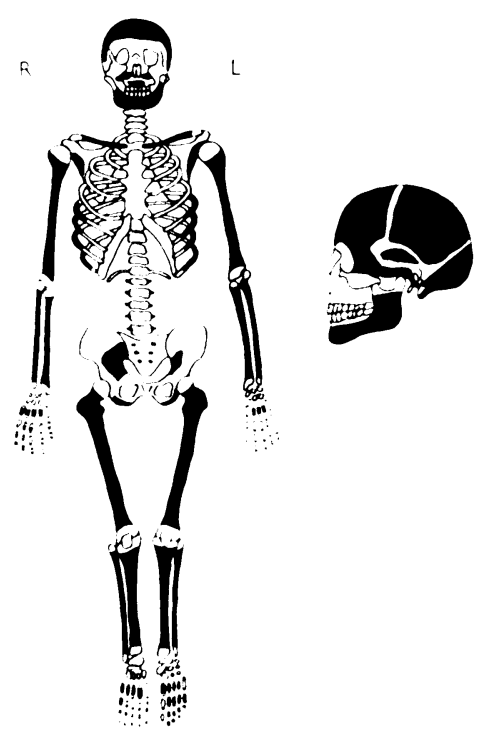

FiG. 15

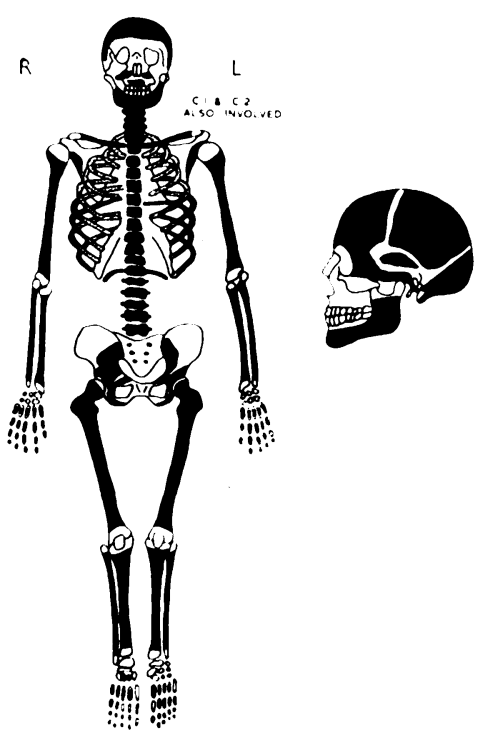

FIG. 16

Figure 15-Schematic representation of skeleton of the patient described in this report. The black shaded areas represent the bones involved and the extent of involvement. Figure 16-Schematic representation of skeleton, with blackened areas representing bones involved in reported cases in world literature. The dotted areas represent bones uncommonly affected.

bodies is increased relative to the height, so that the bodies do appear flattened, and this is particularly noticeable in the cervical spine. There is no increase in density; if anything, the bodies are slightly more translucent than normal.

The metatarsals and metacarpals have shown bilateral, but not always symmetrical, involvement in five patients, and the phalanges in two patients.

\section{DIFFERENTIAL RADIOLOGICAL DIAGNOSIS}

The similarities existing between Engelmann's disease, leontiasis ossea with generalised bone changes and hyperostosis generalisata with pachydermia have already been mentioned. Sear (1948) suggested that the well known-but uncommon-bone disorders, osteopetrosis and melorheostosis, may be related conditions.

When one bone is affected, before a diagnosis of Engelmann's disease can be made, Garre's osteomyelitis, Brodie's abscess, osteoid osteoma and neoplasm must be excluded.

When many bones are involved many diseases must be considered in the differential diagnosis, such as renal osteodystrophy, fibrous dysplasia, infantile cortical hyperostosis, 
fluorosis, and heavy metal poisoning. A severe form of Engelmann's disease in the older age groups may resemble myelosclerosis, Paget's disease or osteoblastic carcinomatosis.

\section{HISTOLOGICAL AND OTHER INVESTIGATIONS}

There has been considerable variation in the histological findings, but this is to be expected when each specimen is of limited size, from different parts of various affected bones in different patients. In the radiologically altered bone there is increased cellularity with new bone formation. Fibrous tissue replacement of muscle fibres occurs. In the arteries proliferation of the intima and media has been seen, as well as in the veins of the subcutaneous tissues, muscle and bone marrow (Singleton et al. 1956, Neuhauser et al. 1948, Le Bien and Heilman 1951).

A multitude of laboratory investigations has usually revealed no abnormality. The patient of Farreras Valenti et al. (1954) had a positive Wassermann reaction.

\section{PROGNOSIS}

The only deaths recorded are those from anaemia at the age of three months (Gvozdanovic 1950) and from pneumonia at fifty-two years (Buchem et al. 1955).

\section{SUMMARY AND CONCLUSIONS}

Engelmann's disease appears to be a familial and probably hereditary systemic condition. in which most of the manifestations can be attributed to a disorder in the osseous and muscular systems. At present the nature of the pathological process is obscure. The manifestations may present soon after birth or become apparent later in life. There is evidence that it is progressive but it may become arrested in some patients.

In order that this very incomplete state of knowledge may be improved it will be necessary to observe patients and their relatives throughout their lifetime.

We would like to thank Dr Hugh Davies for his valuable advice and help and Dr S. P. Meadows for permission to publish the case. Our thanks are also due to the Medical Committees of the National Hospital for Nervous Diseases and of the Hospital for Sick Children for allowing us access to their archives. We would also like to thank Mr A. H. Prickett of the Photographic Department of the Institute of Neurology for the photographs, and the secretarial staff of the Radiographic Department for preparing the manuscript.

\section{REFERENCES}

Anderson, F. G. (1953): Engelmann's Disease. British Journal of Radiology, N.S. 26, 603.

ANgel. J. H. (1957): Pachydermo-periostosis (Idiopathic Osteoarthropathy). British Medical Journal, ii, 789. BiNGold, A. G. (1950): “ Engelmann’s Disease," Osteopathia Hyperostotica (Sclerotisans) Multiplex Infantilis: Progressive Diaphysial Dysplasia. British Journal of Surgery, 37, 266.

Buchem, F. S. P. van, Hadders, H. N., and Ubrens, R. (1955): An Uncommon Familial Systemic Disease of the Skeleton: Hyperostosis Corticalis Generalisata Familiaris. Acta Radiologica, 44, 109.

Caffey, J. (1956): Pediatric X-ray. Diagnosis. Third edition, p. 817. Chicago: The Year Book Publishers Inc.

Camurati, M. (1922): Di un raro caso di osteite simmetrica ereditaria degli arti inferiori. Chirurgia degli Organi di Movimento, 6, 662.

Casuccio, C. (1949): Osteopatie rare, p. 432. Bologna: Edizioni Scientifiche Istituto Rizzoli.

Cocchi, U. (1951): Hereditary Diseases with Bone Changes. In Roentgen Diagnostics. By H. R. Schinz. W. E. Baensch, E. Friedl and E. Uehlinger. Vol. 1, Part 1, Section K, p. 702. London: William Heinemann Medical Books Limited.

Cockayne, E. A. (1920): Case for Diagnosis. Proceedings of the Royal Society of Medicine (Section for the Study of Disease in Children), 13, 132.

Coolbaugh, C. C. (1952): Effects of Reduced Blood Supply on Bone. American Journal of Physiology, 169, 26. (Cited by Singleton.)

Engelmann, G. (1929): Ein Fall von Osteopathia hyperostotica (sclerotisans) multiplex infantilis. Fortschritte auf dem Gebiete der Röntgenstrahlen, 39, 1,101.

Fairbank, Sir T. (1951): An Atlas of General Affections of the Skeleton. Edinburgh and London: E. \& S. Livingstone Ltd.

VOL. 43 B, NO. 2, MAY 1961 
Farreras Valenti, P., Vilaseca, J. M., and de Caralt, M. (1954): Osteosclerosis diafisaria múltiple hereditaria tipo Camurati-Engelmann con sindrome de leontiasis ósea. Revista Española de Reumatismo, 5, 354.

Fediema, cited by RibBing, S. (1949).

Feld, H., Switzer, R. A., Dexter, M. W., and Langer, E. M. (1955): Familial Metaphyseal Dysplasia. Radiology, 65, 207.

Fritsch, H. (1933): Ein Fall von generalisierter Osteosklerose. Wiener Archiv für Innere Medizin, 23, 247.

Garland, L. H. (1946): Generalized Leontiasis Ossea. American Journal of Roentgenology, $55,37$.

Geschickter, C. F., and Copeland, M. M. (1949): Tumors of Bone. Third edition, p. 765. Philadelphia, London, Montreal: J. B. Lippincott Company.

GillespIE, J. B., and Mussey, R. D. (1951): Progressive Diaphyseal Dysplasia (Engelmann's Disease). Journal of Pediatrics, 38, 55.

Griffiths, D. LI. (1956): Engelmann's Disease. Journal of Bone and Joint Surgery, 38-B, 312.

Gulledge, H. W., and White, J. W. (1951): Engelmann's Disease (Progressive Diaphyseal Hyperostosis). Report of a Case. Journal of Bone and Joint Surgery, 33-A, 793.

Gvozidanović, V. (1950): Ein neuer Fall von Engelmannscher Krankheit. Beitrag zur Kenntnis der kongenitalen Osteodystrophien. Fortschritte auf dem Gebiete der Röntgenstrahlen, 73, 86.

Jackson, W. P. U., Hanelin, J., and Albright, F. (1954): Progressive Diaphyseal Dysplasia. Archives of Internal Medicine, 94, 902.

Jammes, A., Seruz, R., Prouxet, J., and Duclos, G. (1953): Maladie d'Engelmann: ostéopathie hyperostosante et sclérosante infantile multiple. (A propos d'une nouvelle observation.) Revue du Rhumatisme, 20, 406. KnAGgs, R. L. (1926): The Inflammatory and Toxic Diseases of Bone. Bristol: John Wright and Sons Ltd.

Komins, C. (1954): Familial Metaphyseal Dysplasia (Pyle's Disease). British Journal of Radiology, N.S. $27,670$.

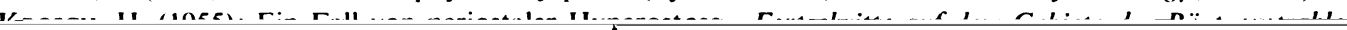

